\title{
The perfect storm of business venturing? The case of entomology-based venture creation
}

\author{
Stefano Pascucci ${ }^{1 *}$, Domenico Dentoni ${ }^{1}$ and Dimitrios Mitsopoulos ${ }^{2}$
}

\author{
* Correspondence: \\ stefano.pascucci@wur.nl \\ ${ }^{1}$ Management Studies Group, \\ Wageningen University, \\ Hollandseweg 1, 6700EW, \\ Wageningen (NL) \\ Full list of author information is \\ available at the end of the article
}

\begin{abstract}
In this paper we discuss how cooperation and trust among entrepreneurs can be challenged when they are dealing with venture creation in the context of radical innovation. Entomology-based foods are considered as one of the most promising innovation in the food sector. However they impose radical changes in food consumption habits with high risk of low consumer acceptance. Four European entrepreneurs joined forces in a new venture operating in this sector, trying to make it a successful business. We asked two of them to participate in a venture creation game experiment. The results indicate that high individualized pay-offs can lead the entrepreneurs to deviate from trust and cooperation.
\end{abstract}

Keywords: Venture creation; Radical innovation; Insects; Prisoner's Dilemma

\section{Background}

The global population is growing rapidly and it is likely to reach 9 billion by roughly the middle of this century (United Nations 2014). It is also predicted that more than 7.5 billion inhabitants will be in the less developed countries while the population of the least developed countries is projected to reach 1.7 billion (United Nations 2014). At the same time the world population is increasingly urbanizing. United Nations predictions indicate that about 70\% of the population to be living in cities by 2050 (United Nations 2014). This rapid urbanization triggers a growing consumption of meat which for developing countries represents the most concentrated source of vitamins and minerals (Tilman et al. 2001). In addition to that, the growing wealth in developed countries as well as emerging economies, such as China, increases the purchase power of the consumers and thus pushing for a greater demand of processed food from meat, fish and dairy (Tilman et al. 2001). The market globalization triggers even more the consumption of meat products and decreases the types of consumed food products (Yen 2009). Moreover still an important percentage of world population do not have access to sufficient proteins (sometimes reaching extreme hunger levels), and even more people suffer from a form of micronutrient malnourishment (Barrett 2010).

Against this background, food and feed from insects appears a promising way to cope with the abovementioned issues (DeFoliart 1997). Insects nowadays are already a major or secondary source of protein elsewhere in the world (i.e. Asia, Africa, Australia and South America). In these areas insects have been a valuable and integral part of the human diet for hundreds of years (DeFoliart 1999) For many countries insects also 
significantly contribute to the local economies (DeFoliart 1999). In recent years attention for insects as new source of food ingredients has raised also in industrialised (Western) countries (Pascucci and de-Magistris 2013). Many concerns have been raised as well, due to regulatory, cultural and psychological barriers to create and develop an entomologybased food and feed industry (Derkzen et al. 2010). However, despite the scepticism of many stakeholders, several start-ups are trying to step in this industry, thus facing all kind of challenges from both a regulatory and marketing point of view. The co-existence of regulatory and marketing challenges makes the venture creation process a unique case, a kind of "perfect storm" of business venturing in the context of agri-food sector, thus calling for specific attention of both academics and practitioners.

In this paper we focus particularly on "how to create a vivid, profit making entomologybased company" in industrialized country context, rather than on general cultural and psychological issues related to insect consumption. In order to answer this research question we first start discussing the issue of new venture creation and radical innovation in the agri-food sector, since eating insects can be perceived as radically innovative in developed countries. We then analyse in more details, what are the main challenges when it comes to setting up a new venture dealing with a radically innovative product, particularly in terms of trust and cooperation within the entrepreneurial team. Based on this conceptual approach we have set-up a "venture creation game experiment" with two entrepreneurs of an European start-up company in the sector of entomology-based food products. In this way we have been able to highlight the main challenges and opportunities of such a business, and namely the role of trust and cooperation. We provide indications for other entrepreneurs and academic scholars who are dealing with venture creation and radical innovation, especially in the agri-food sector. While consumer acceptance remains the dominant (background) strategic issue for an entomology-based start-up company, our results indicate that trust and cooperation between business partners is one of the main challenges for the success of a start-up dealing with a radical innovation.

\section{Methods}

Literature review

\section{Insects as sustainable source of protein}

From an historical point of view considering insects as food is not something new in Western societies. Greeks and Romans were consuming several kinds of insects (like grasshoppers and beetle larvae) which they considered delicacies (DeFoliart 1999). Nowadays consumers eat ingredients derived from insects mainly as additives or accidentally through the food processing. For example, an additive called carmine or cochineal is commonly used to add a red/pink colour to many food products such as yogurts, candies and drinks (Greenhawt and Baldwin 2008). This ingredient is a pigment of a bright-red colour obtained from specific insects (cochinidae), and it is coded as E120 in the food labelling process. A couple of years ago, the US Food and Drug Administration set up a rule requiring food companies to list cochineal extract and carmine on their labels when they are used in food products or cosmetics, but it does not require companies to indicate that these ingredients are derived from insects (van Huis 2013).

In general the level of protein and fats in all insect species is high, and on average much higher than the traditional sources of proteins (Cerritos 2009). The nutritional characteristics of insect proteins are also very interesting. Some insects have proteins of 
high quality and of high digestibility (77-98\%), and the concentration of essential amino-acids is also high (46-96\% of the nutritional profile) (Verkerk et al. 2007). In addition to that, insects have many vitamins, provide high energy, minerals and fibre. Some insects have higher contents of calcium, magnesium, iron, and potassium than those of most food products of vegetable or animal origins. The caloric value of some insects is $50 \%$ higher than soybeans, $87 \%$ higher than maize, $63 \%$ higher than beef, and $70 \%$ higher than fish and beans (Verkerk et al. 2007).

Raring insects can also have many potential advantages in comparison with the current livestock production. Insects need fewer inputs to give production as they have high efficiency to convert biomass to protein (Oonincx and de Boer 2012). Of course the food conversion efficiency depends on high-quality diets, and livestock conditions (DeFoliart 1997; Cerritos 2009). Moreover, insects as poikilothermic animals do not spend large amounts of energy and nutrients to maintain constant their body temperatures. Thus, they are more efficient in transforming plant biomass into animal biomass (DeFoliart 1999). Insects are also big energy saver as they produce less waste in terms of manure and ammonia (Oonincx and de Boer 2012). In addition to that, insects can utilize many of the indigenous resources not used by humans, as well as organic wastes (Ramos-Elorduy 1997).

The first introduction of insects in the food supply chain was as an alternative for the expensive fish meal and for pet food industry as there was an increasing need of high-protein feed. However until now insects have not been massively produced for human consumption in Western societies (Pascucci and de-Magistris 2013). Using insects as source of ingredients for food products is a quite radical idea in this context, and it requires dramatic changes in the existing and dominating food consumption habits (Pascucci and deMagistris 2013; Derkzen et al. 2010). This is probably the main reason why insect-based food products can be considered a radical innovation in the agri-food industry. It is not just a minor incremental extension of current food products, but a more a ground-breaking concept. For the mass production of this novel food there is a need for technology which is a bundle of brand new knowledge, skills and equipments (Carayannis et al. 2003). Often innovation in the agri-food industry combines technological innovation with social and cultural innovation (Earle 1997; Capitanio et al. 2009). Insect food is not just a novelty or an improvement, it is a fundamental change, a cultural "step-jump" in terms of food consumption habits. Often, radical innovations are not introduced on the market because consumers are very risk-adverse, and they are reluctant to accept new products. Radical product innovations are new to their users, or are radical in terms of creating disruptions in existing usage patterns (Heiskanen et al. 2007). This kind of innovations breaks with traditions in their field. There are many similarities between consumer acceptance of radical products and technologies and food innovations. However due to both cultural and psychological issues related to insect-based food products, risks of consumer rejection and failures is even higher than other "technology-based" radical innovations (Pascucci and de-Magistris 2013).

\section{New venture creation in the context of radical innovation}

The failure rate of new ventures is in the most optimistic research estimated to be around 46\% (Timmons and Spinelli 2009 p.106). This number shows the huge difficulties most entrepreneurs face in creating their company. In this section an overview is provided of what is written about the entrepreneurial process and the steps in order to create a New Venture (NV). 
New Venture Creation (NVC) starts with an idea. To verify if an idea is a valuable opportunity, entrepreneurs need to invest in thorough research and investigate organizational as well as market feasibility. In assessing the feasibility of a NV opportunity there are basically four primary areas entrepreneurs can look at (Gundry and Kickul 2007 p. 63-64): (i) team dynamics, such as cooperation and trust, (ii) availability of resources, (iii) knowledge and information and (iv) ability to generate revenue. Particularly understanding the quality of team dynamics requires time in order to find out which team members fit the entrepreneurial idea, whether they are good co-operators, and assess their trustworthiness (Timmons and Spinelli 2009 p. 188). Solid and cooperative teams are far more likely to attract venture capital (Mason and Stark 2004) than companies that do not. It is clearly stated that in order to create a vivid NV, there must be trust, cooperation and reciprocity between team members. Thus putting together key team members and create trust between them is a crucial part of NVC, because "who is added to a team affects not just the content or the capacity of the team, but also how the team does what it does" (Forbes et al. 2006). The leader of a NV has to show interest, create and spread passion and have a clear vision of where to go. However balancing individual and team/collective interests is a difficult task often leading a prisoner's dilemma condition in NV (Cable and Shane 1997). Cooperation among partners is also important to define the right financing strategy of the NV and to cover initial start-up costs. In the initial financing stage, most companies get financed by personal savings, loans from friends and relatives (with or without interest) (Bessant and Tidd 2007 p. 276), and/or the use of a personal credit card (Gundry and Kickul 2007 p.177). Setting up the right incentives and balancing between individual and team-based risks and pay-offs is a key-factor for successful NVC. Moreover because financial resources are often very scares for NV, an often used strategy is to align with complementary partners and form strategic alliances (Koza and Lewin 1998). This can lead to advantages such as product improvement, technology advancements, increase of future strategic planning capabilities. Also the process of creating strategic alliances, therefore expanding the original team to other members and groups, requires trust and cooperation among entrepreneurs in the NVC process.

While VC is challenging per se, associating it to creation of new products and/or processes can be even more challenging. Innovations follow a similar pattern as VC. They start with an idea, followed by the evaluation of that idea. A way to think about innovation is also to think about the degree of novelty it is bringing up. In this respect we have to make a distinction between an incremental innovation and a radical innovation, or "Doing what we do better" versus "New to the world" (Bessant and Tidd 2007 p.15). In order to examine whether a product is really new-to-the-world, Markides and Geroski (2005 p.4), posed two conditions which have to be met:

1) They offer new value propositions that radically change existing consumer habits and behaviour.

2) "The markets they create undermine the competences and complementary assets on which competitors built their success".

When NVC is associated to a radically innovative (RI) product is calling for understanding very specific circumstances. As distinct from NVC with a "normal" product, setting up a business with a RI product means taking higher risk and, in most cases, 
involving uncertainty of the highest degree. When it comes to innovation in NVC, we can consider different elements (Bessant and Tidd 2007 p. 40) such as personal or individual level which focuses on the role of creativity and entrepreneurship, the collective or social level that focuses on the importance of team dynamics and the context. Creativity involves not only finding bright ideas; it also deals with the thousands of problems arising in the NVC process. This creativity needs to be in balance with control on time, money and key resources. In order to establish a successful new venture with a RI product, entrepreneurs need to develop leadership and rely on several factors (Bessant and Tidd 2007 p.42) such as the ability to gather information from a wide range of sources, ability to give meaning to information, ability to reduce/change routines/existing behaviours and the ability to solve problems at an early stage. Entrepreneurial teams dealing with RI also need to rely on complementary skills, thus combining all kinds of knowledge to give the NV valuable insights on marketing aspects, financial issues and product development. Moreover they need to develop specific features of leadership. For example due to high uncertainty, the leader and the management team should have a clear overview of the process. They need to develop the ability to work together such that the structure of the organisation can allow people to deploy their creativity and share their knowledge. (Bessant and Tidd 2007 p.19 and p.27). It is also highlighted the relevance of learning from mistakes and to build proactive links between boundaries in and outside the organisation like in a "multi-player game" (Bessant and Tidd 2007 p. 20). In order to maintain an innovation-friendly environment, entrepreneurs have to encourage experimentation. It also might help to visit other companies and customers' organisations regularly, and get the management team inspired by new ideas and other routines (Gundry and Kickul 2007 p. 306). Another way to ban out uncertainty in the NVC process with a RI product, is research and development (R\&D). This mainly focuses on the product design part. In normal NVC, the $R \& D$ phase usually covers the first one and a half years (Timmons and Spinelli $2009 \mathrm{p}$. 309). For NVC with a radical innovation this might be even longer. For the amount of investment needed, probably the same holds. Also, there is the risk of failure to get financial support to support and develop your ideas. Support from inside and outside the organisation is in fact necessary.

The case study: a venture creation dilemma in "Company $\mathrm{X}$ "

Challenges imposed by RI products are all very important for testing trust and cooperation in an entrepreneurial team dealing with a NVC. To empirically test this issue we developed a prisoner's dilemma based experiment with entrepreneurs involved in a real start-up company engaged in entomology-based products.

Company $\mathrm{X}$ is a venture located in Western-Europe funded by four entrepreneurs in the autumn 2011. They all have different backgrounds, namely in the technical field (LCA analyst), management and marketing. Moreover, they have a world-class chef in their team.

The general vision of Company X can be summarized as follow: "insect is a promising solution to meet the growing demand for animal proteins when traditional sources are reaching their environmental limits". As showed by Figure 1 company $\mathrm{X}$ believes that insects should not be eaten for fun, as rare delicacies sold at a luxury price. Instead, they strongly believe that insects are a serious opportunity to improve food 


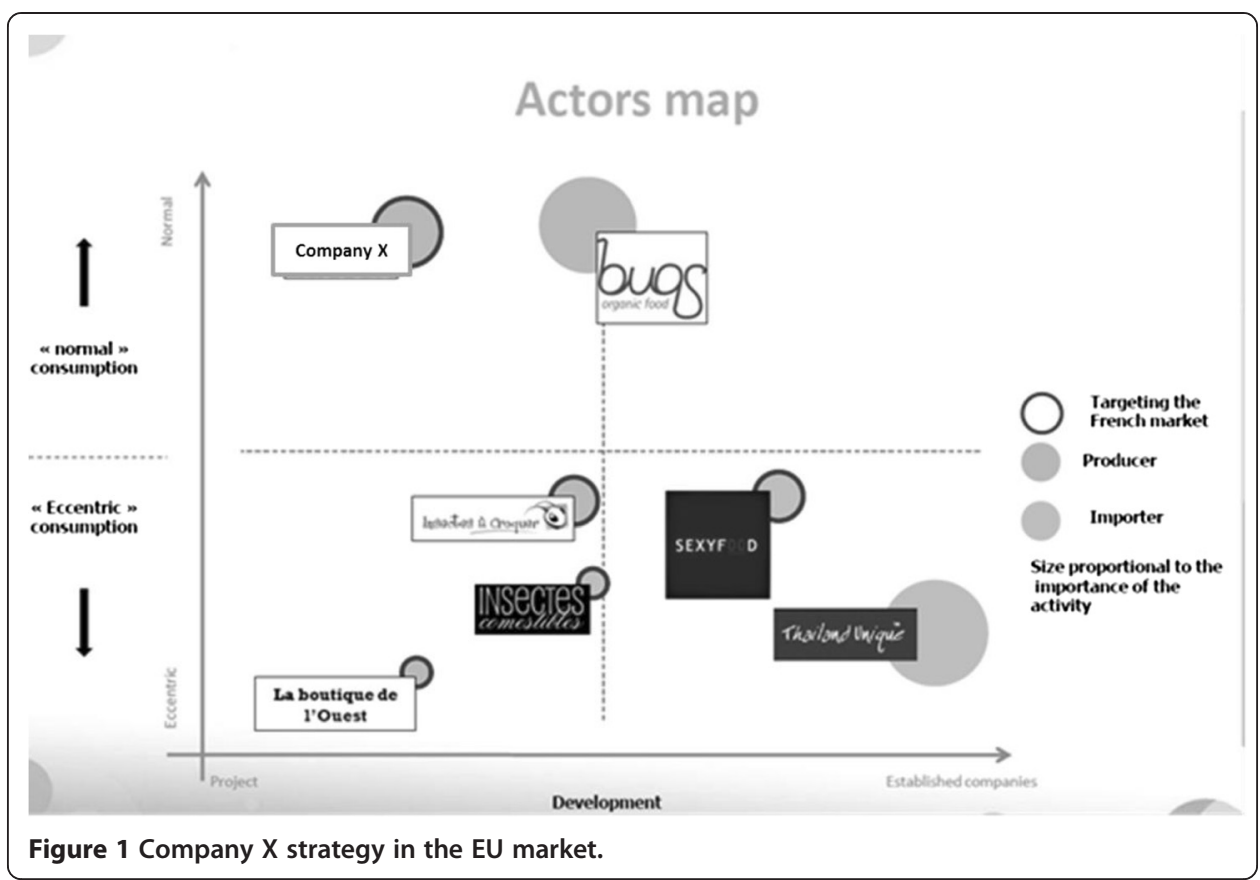

consumption habits, because they show great value for health and the environment. This is differentiating their strategy compared to their competitors' ones (Figure 1). Coherent with their strategy the four entrepreneurs have settled a mission for achieving their mid-term objectives, such as "creating, preparing and sale on the European territory, products prepared with insects and intended for human consumption". Company $\mathrm{X}$ mid-term objective is to produce and sell edible insect-based products, in which the insect will be made invisible. Currently, the entrepreneurs are working on differential studies regarding biochemical properties of insects and consumer acceptance. The Management Studies (MST) department from Wageningen University (NL) has played an important role in the latter. Besides this, the company focuses on developing industrialsize processing plants. The cooperation between Company X and Wageningen University, aims at four marketing topics, as posed by Company X:

1. Analysing the mental representations regarding insects and more especially regarding insects as food;

2. Determining drivers and barriers to insect-based products;

3. Qualifying an quantifying the main targets;

4. Understanding the main targets of consumer habits in order to integrate our products in their frame of consumption.

The experiment was held in the late December 2011. To reduce hypothetical biases due to unrealistic options we inform the entrepreneurs that we were asking them to participate to a program lead by an European funding institution. We frame the participation indicating that the program would be funded in the next future conditional to budget availability. We framed the participation indicating that the results would have been considered for shortlisting potential candidates. We also asked to consider the participation in the program within 
the more general agreement Company X has arranged with Wageningen University. Two of the four entrepreneurs were asked to participate. They were the two in charge for financial and marketing strategy of the company respectively. We clarified the procedure with the two players and make sure they were understanding the role for the game.

More specifically we double-checked on the reward mechanism: only if both of them would have chosen the same solution in each option round, then they would have been considered as potential candidate to be really funded in a later stage. They both know that the probability of being successful would have been conditional on the otherplayer choice. We ran the experiment separately. We made sure that the two entrepreneurs couldn't communicate or transfer information.

The experiment has been designed following theoretical insights from Cable and Shane (1997). The essence of a Prisoner's Dilemma game is that "each individual actor has an incentive to act according to competitive, narrow self-interest even though all actors are collectively better off (receive higher rewards) if they cooperate" (Cable and Shane 1997 p. 145). To display this graphically, a general payoff matrix is introduced in Table 1:

Where $\mathrm{R}$ = reward when both players cooperate; $\mathrm{P}=$ punishment when both players defect; $\mathrm{S}$ = sucker's Payoff (penalty for cooperation while the other defects); T = temptation by extra payoff from defection (Cable and Shane 1997). Such that the payoffs for each player are dictated by the strategy adopted by the other player and follow the payoff structure $\mathrm{T}>\mathrm{R}>\mathrm{P}>\mathrm{S}$ (Cable and Shane 1997). In the context of this experiment ${ }^{\mathrm{b}}$ we decided to check for two elements of cooperation and trust:

1) whether the two players (entrepreneurs) were committed to the original strategy of the company (strategy A) or deviating for a strategy which was rewarding them more (strategy B);

2) whether the two players were committed to (lower) team-based rather than (higher) individual based rewards.

Therefore to let the experiment be incentive compatible and considering we were testing "temptation to defect", so whether the player is willing to give up "cooperation and trust" for an "individual-oriented reward", we made more attractive to deviate rather than cooperate. However punishing for simultaneous defection was not feasible. Therefore original payoff structure has been changed such that $T>R>P=S$. In other words we made the pay-off of being "sucked" and the punishment equal. Introducing a punishment payoff (such as a fine to be paid by one of the entrepreneur to the other one would have made the experimental setting unrealistic). However the incentive compatibility principle has been preserved.

In this way we could assess the value of cooperation against defection (individualised rewards). We used a change in strategy as a treatment to mitigate or increase

Table 1 Prisoners' dilemma game setting

\begin{tabular}{llll}
\hline & & Player 2 & \\
\cline { 3 - 4 } & & Cooperates & Defects \\
\hline Player 1 & Cooperates & $R, R$ & $S, T$ \\
& Defects & $T, S$ & $P, P$ \\
\hline
\end{tabular}


"temptation to deviate". As said strategy A is reflecting the original strategy of Company $\mathrm{X}$, which can be described as follow:

- Vision: "The insect is a promising solution to meet the growing demand for animal proteins when traditional sources are reaching their environmental limits"

- Mission: "The creation, preparation and sale on the European territory of products prepared with insects and intended for human consumption"

- Target consumers: "Normal consumers, willing to try new products but not driven by eccentric consumption habits. Avoiding niche and specialized markets. Supermarket as main outlet. Premium price for being healthy products and not luxury/exclusive products (such as delicatessen). Avoiding visualization of insects".

We proposed an alternative strategy that would possibly generate higher financial rewards and lower risks. We call it "strategy B". Since this strategy is challenging the current strategy, which was agreed in a team-based setting, we considered strategy B as an indication to deviate from cooperation and deviation from "trust in the group leadership". The vision and mission stay the same as in strategy A, but a different target group of consumers is addressed:

- Target consumers: "Environmental oriented and sensitive consumers, willing to experience new products. It is a niche product, targeting consumer buying groups or consumers cooperatives. Strong association with organic foods (premium price due to credence features). Avoiding visualization of insects".

The alternative business strategy is not yet proven to be a successful strategy for a new venture is the entomology-based business. Though it definitely has, according to preliminary marketing analysis, the potential to generate revenue with a relatively low amount of business risk (Table 2).

Where $\mathrm{R}$ = reward when both players cooperate; $\mathrm{P}=$ punishment when both players defect; $\mathrm{S}=$ sucker's payoff (penalty for cooperation while the other defects); $\mathrm{T}=$ temptation by extra payoff from defection (Cable and Shane 1997). Such that the payoffs for each player are dictated by the strategy adopted by the other player and follow the payoff structure $\mathrm{T}>\mathrm{R}>\mathrm{P}=\mathrm{S}$. The option choice as displayed in Table 3 is one of the 8 decisionscenarios used in the case of Campany $\mathrm{X}^{\mathrm{c}}$. In this example the two entrepreneurs have to choose between an individual-based reward (10,000 euro) and a team-based award (divide $€ 10.000$ over 4 team members). The outcome of such a venture creation game is that both entrepreneurs are better off when they cooperate, because in case of one entrepreneur

Table 2 Venture creation game for testing defection from cooperation

\begin{tabular}{llll}
\hline & Player $\mathbf{2}$ & \\
\cline { 3 - 4 } & Cooperates (Team-based reward) & Defects (Individual-based reward) \\
\hline Player 1 & $\begin{array}{l}\text { Cooperates } \\
\text { (Team-based reward) } \\
\begin{array}{l}\text { Defects } \\
\text { (Individual-based reward) }\end{array}\end{array}$ & T,S & S,T \\
\hline
\end{tabular}


Table 3 Example of a pay-off matrix in one of the option of the venture creation game

\begin{tabular}{llll}
\hline & & Player 2 & \\
\cline { 3 - 4 } & & Cooperates & Defects \\
\hline Player 1 & Cooperates & 2500,2500 & 0,5000 \\
& Defects & 5000,0 & 0,0 \\
\hline
\end{tabular}

defecting, they do not get anything. This makes clear that cooperation in an entrepreneurial management team is very important.

\section{Results and discussion}

In Table 4 we present the results obtained in the experiment. As said the entrepreneurs were exposed to 8 decision-scenarios in which they have to decide whether to opt for a cooperative rather than individualistic solution. In the first two scenarios cooperation was achieved since both entrepreneurs indicate team-based stakes as preferred to individual based. Scenario 1 can be considered as the benchmark since it is proposing no incentive to deviate (both in terms of financial stakes and strategy seeking). In scenario 2 a small incentive to deviate was introduced, since strategy treatment would have lead for a less risky solution. However from scenario 3 to scenario 8 player 2 systematically deviated for more individualistic based rewards.

In an ex-post interview we asked the two entrepreneurs to motivate their decisions. While player 1 indicated that he was keen on pursuing team-based options, no matters the stakes indicated in the experiment, player 2 was indicating budget-seeking behaviour at the base of his choice. In short she indicated that given the early stage of their business, it was more important to look at options where more financial resources were provided. He also argued that at this stage it was not relevant whether financial resources would have been granted to the team or at least to one of its member. Player 1 is the initiator and main promoter of the venture, while player 2 is the expert in marketing and institutional relations. The different role they play in the company can explain their different decisions.

\section{Conclusions}

In recent years attention for novel sources of food ingredients and especially proteins is raising worldwide. Particularly in industrialised countries the idea of using insects is gaining consensus among a number of young start-ups. However despite their optimism, a number of concerns have been raised due to regulatory, cultural and

Table 4 Results of the venture creation game with Company $X$

\begin{tabular}{lllll}
\hline Scenario & Strategy treatment & Individual-based reward (T) & Team-based reward (R) & Result \\
\hline 1 & No & 2,500 & 2,500 & Cooperation \\
2 & Yes & 2,500 & 2,500 & Cooperation \\
3 & No & 5,000 & 2,500 & Player 2 defected \\
4 & Yes & 5,000 & 2,500 & Player 2 defected \\
5 & No & 10,000 & 5,000 & Player 2 defected \\
6 & Yes & 10,000 & 5,000 & Player 2 defected \\
7 & No & 20,000 & 5,000 & Player 2 defected \\
8 & Yes & 20,000 & 5,000 & Player 2 defected \\
\hline
\end{tabular}


psychological barriers. In this paper we have framed the co-existence of these regulatory and marketing challenges as the "perfect storm" of business venturing in the agrifood sector. Particularly we have focused on the issue of "how to create a vivid, profit making entomology-based company" in industrialized countries, rather than on general cultural and psychological issues related to insect consumption. We tried to answer this research question firstly by discussing the issue of new venture creation and radical innovation in the agri-food sector. Literature and empirical evidence highlight that new venture creation is a risky operation. When dealing with a radical (food) innovation the risks are even higher. There are three clear challenges which can be derived from the literature review such as issues of (i) consumer acceptance, (ii) financial resource capabilities, and (iii) building strategic alliances. However before dealing with those challenges, entrepreneurs involved in new venturing have to deal with ensuring a good level of cooperation and trust in their business environment. When dealing with radically innovative products this is even more important. Starting form this conceptual consideration, we have analysed in more details what are the specific challenges when it comes to setting up a new venture dealing with a radically innovative product, in an entomology-based start-up (company X). More specifically we have set-up a "venture creation game experiment" to highlight the main challenges and opportunities of such a business, and namely the role of trust and cooperation. Results indicate that while consumer acceptance remains the dominant strategic issue for an entomology-based start-up company, trust and cooperation between entrepreneurs is one of the main challenges for the success of a start-up dealing with a radical innovation. Therefore a vivid, profit-making entomology-based company is best created when the entrepreneurial team has been based on strong trust and cooperation principles. What has to be kept in mind is that total commitment to the team is essential and the prisoner's dilemma based experiment has been a way to find out the team cohesion and willingness to cooperate.

Of course given the number of observations and the specificity of this type of food innovation we are carefully constrained in drawing more general conclusions. However the use of experiments to assess entrepreneurs behaviour, their "social preferences", such as trust and cooperation, is indeed encouraging. The next step will be to implement experiments at a larger scale and to use as real as possible pay-off. This will increase the realism of results and the power of prediction of the analysis.

\section{Endnotes}

${ }^{a}$ We use "Company X" to preserve confidentiality. More detailed information on the company and the experiment can be asked to the authors.

${ }^{\mathrm{b}}$ The description of the experiment is reported in Appendix A

${ }^{\mathrm{c}}$ See Appendix A for all the other options proposed in the experiment.

Competing interests

The authors declare that they have no competing interests.

Authors' contributions

SP prepared the background section, the case study analysis section, the results and discussion section. DD the conclusions section. DM the literature review. All authors read and approved the final manuscript.

Author details

${ }^{1}$ Management Studies Group, Wageningen University, Hollandseweg 1, 6700EW, Wageningen (NL). ${ }^{2} \mathrm{MSc}$ Organic Agriculture, Consultant in Agribusiness Marketing and Innovation, Wageningen (NL). 
Received: 22 July 2014 Accepted: 12 December 2014

Published online: 07 February 2015

\section{References}

Barrett CB (2010) Measuring food insecurity. Science 327(5967):825-828

Bessant J, Tidd J (2007) Innovation and entrepreneurship. John Wiley \& Sons Inc, Chichester, England, p 462

Cable DM, Shane S (1997) A prisoner's dilemma approach to entrepreneur-venture capitalist relationships. Academy of Management Review 22(1):142-176

Capitanio F, Coppola A, Pascucci S (2009) Indications for drivers of innovation in the food sector. British Food Journal 111(8):820-838

Carayannis EG, Gonzalez E, Wetter J (2003) The nature and dynamics of discontinuous and disruptive innovations from a learning and knowledge management perspective, vol The international handbook on innovation (Part II)

Cerritos R (2009) Insects as food: an ecological, social and economical approach. CAB Rev: Perspect Agr Vet Sci Nutr Nat Resour 4(027):1-10

DeFoliart GR (1997) An overview of the role of edible insects in preserving biodiversity. Ecol Food Nutr 36(2-4):109-132

DeFoliart GR (1999) Insects as food: why the western attitude is important. Annu Rev Entomol 44:21-50

Derkzen P, Dries L, Pascucci S (2010) Conceptualizing the acceptance of insect-based food ingredients in western diets. Proceedings of the $5^{\text {th }}$ International Consumer Sciences Research Conference on "Consumer Behaviour for a Sustainable Future". University of Bonn, Bonn, Germany

Earle MD (1997) Innovation in the food industry. Trends Food Sci Technol 8(5):166-175

Forbes DP, Borchert PS, Zellmer-Bruhn ME, Sapienza HJ (2006) Entrepreneurial Team Formation: An Exploration of New Member Addition. Entrepren Theor Pract 30(2):225-248

Greenhawt M, Baldwin JL (2008) Food colorings and flavors. Food Allergy: Adverse Reactions to Foods and Food Additives, 4th edn. John Wiley \& Sons, New York, pp 403-428

Gundry LK, Kickul JR (2007) Entrepreneurship strategy - Changing Patterns in New Venture Creation, Growth, and Reinvention. Sage Publications, California, p 401

Heiskanen E, Hyvönen K, Niva M, Pantzar M, Timonen P, Varjonen J (2007) User involvement in radical innovation: are consumers conservative? Eur J Innovat Manag 10(4):489-509

Koza MP, Lewin AY (1998) The Co-Evolution of Strategic Alliances. Organ Sci 9(3):255-264

Markides C, Geroski PA (2005) Fast Second - How smart companies bypass radical innovation to enter and dominate new markets. John Wiley and Sons, San Francisco

Mason C, Stark M (2004) What do Investors Look for in a Business Plan? Int Small Bus J 22(3):227-248

Oonincx DG, de Boer IJ (2012) Environmental impact of the production of mealworms as a protein source for humans-a life cycle assessment. PLoS One 7(12):e51145

Pascucci S, de-Magistris T (2013) Information bias condemning radical food innovators? The case of insect-based products in the Netherlands. Int Food Agribusiness Manag Rev 16(3):1-16

Ramos-Elorduy J (1997) Insects: A sustainable source of food?. Ecology of food and nutrition 36(2-4):247-276

Tilman D, Fargione J, Wolff B, D'Antonio C, Dobson A, Howarth R, Schindler D, Schlesinger WH, Simberloff D, Swackhamer D (2001) Forecasting agriculturally driven global environmental change. Science 292(5515):281-284

Timmons JA, Spinelli S (2009) New Venture Creation - Entrepreneurship for the 21st Century (8 ${ }^{\text {th }}$ edition). McGraw-Hill, New York, p 666

United Nations (2014) World Urbanization Prospects: The 2012 Revision. Available at visit http://esa.un.org/wpp/ (Accessed at 17 July 2014)

van Huis A (2013) Potential of insects as food and feed in assuring food security. Annu Rev Entomol 58:563-583

Verkerk MC, Tramper J, Van Trijp JCM, Martens DE (2007) Insect cells for human food. Biotechnol Adv 25(2):198-202

Yen AL (2009) Edible insects: Traditional knowledge or western phobia? Entomologic Res 39:289-298

\section{Submit your manuscript to a SpringerOpen ${ }^{\circ}$ journal and benefit from:}

- Convenient online submission

- Rigorous peer review

- Immediate publication on acceptance

- Open access: articles freely available online

- High visibility within the field

- Retaining the copyright to your article 